\title{
TUTELA ANTECIPADA ANTECEDENTE ESTABILIZADA: POSSIBILIDADE DE DESCONSTITUIÇÃO POR AÇÃO RESCISÓRIA
}

\author{
Advance guardianship stabilization in antecedent character: possibility of \\ unconstitution by rescissory action
}

\author{
Paula Ongaratto Trentin ${ }^{1}$
}

\footnotetext{
${ }^{1}$ Graduanda do sexto semestre em Ciências Sociais e Jurídicas na Universidade Regional Integrada do Alto Uruguai e das Missões - URI Erechim.E-mail: paula_trentin@hotmail.com
}

Data do recebimento: 30/08/2019 - Data do aceite: 09/04/2020

RESUMO: Diante da mora do processo comum, houve a necessidade de criar meios que melhor distribuíssem o ônus do tempo, a fim de que a demora no deslinde do feito não viesse a causar maiores danos a quem tem, a princípio, melhor direito. Nesse ínterim, o Código de Processo Civil de 2015 inovou ao criar as tutelas provisórias. Todavia, apesar dos evidentes benefícios trazidos pela cognição sumária, o legislador cria verdadeira anomalia jurídica ao possibilitar que a tutela provisória de urgência antecipada requerida em caráter antecedente se estabilize, fazendo com que uma decisão provisória se torne definitiva e até mesmo imutável. Assim, sem maior análise do mérito ou discussão da lide, a decisão torna-se estável se não houver interposição de agravo de instrumento no prazo de 15 dias, e definitivamente estável se não houver interposição de ação exauriente em dois anos, divergindo os doutrinadores e o judiciário acerca da possibilidade de interposição de ação rescisória para sua desconstituição e discussão em caráter exauriente. Para a realização da pesquisa utilizou-se o método indutivo, com consulta bibliográfica, tendo como fontes livros, artigos e a legislação brasileira.

Palavras-chave: Tutela de Urgência Antecipada Requerida em Caráter Antecedente. Estabilização da Tutela Provisória. Ação Rescisória.

\footnotetext{
ABSTRACT: Due to delays in the common process, there was a necessity to create means that would better distribute the burden of time, so that the delay in
} 
the demarcation of the deed would not cause greater harm to those who have, in principle, a better right. In the meantime, the 2015 Code of Civil Procedure innovated by creating provisional measures. However, in spite of the evident benefits brought by summary cognition, the legislator creates a real legal anomaly by allowing the Stabilization of Provisional Urgent Advance Guardianship in antecedent character, making that a provisional decision become definite and even immutable. Thus, without further analysis of the merits or discussion of the dispute, the decision becomes stable, if no interlocutory appeal is filed within 15 days. It gets definitely stable, if no exhaustive action is filed within two years, diverging the indoctrinators and the judiciary about the possibility of filing a rescission action for its unconstitution and exhaustive discussion. The research was carried out through inductive method, with bibliographical review, having books, articles and the Brazilian legislation as sources.

Keywords: Urgent Advance Guardianship in Antecedent Character. Stabilization of Provisional Guardianship. Rescissory Action.

\section{Introdução}

O presente artigo propõe uma breve reflexão acerca das tutelas provisórias no âmbito do processo civil, em especial da tutela provisória de urgência antecipada requerida em caráter antecedente e de suas peculiaridades. O surgimento das tutelas provisórias está ligado à demora do Judiciário e ao poder-dever estatal de prestar a jurisdição de forma justa e eficaz. Assim, pela necessidade de inversão ou de supressão do ônus do tempo, ante a probabilidade do direito e o perigo da demora, o legislador cria meios para que a tutela jurisdicional alcance seus objetivos.

Nesse toar, fundando-se na cognição sumária, em um curto espaço de tempo e por meio de uma análise superficial do mérito, é permitido ao juiz a concessão das tutelas provisórias, no caso de preenchimento dos requisitos legais específicos de cada uma delas. Assim, o novo Código de Processo Civil permite que situações injustas sejam minimizadas e até mesmo evitadas. Todavia, por fundar-se em cognição sumária, sendo concedida até mesmo liminarmente em alguns casos, é preciso que haja, posteriormente, profunda análise da lide, em cognição exauriente, respeitados o contraditório e ampla defesa, dando-se a oportunidade ao réu para que exponha sua versão dos fatos.

Verifica-se que, com exceção da tutela provisória de urgência antecipada requerida em caráter antecedente, todas as demais espécies de tutela provisória garantem a ampla discussão do mérito, bem como o contraditório, estando de acordo com o Estado Democrático de Direito e a Constituição de 1988. Entretanto, esta modalidade de tutela provisória em específico, traz a possibilidade de estabilização temporária e até mesmo definitiva de sua decisão concessiva, tornando imutável uma decisão fundada em cognição sumária, sem debate em contraditório.

Ademais, destaca-se a existência de uma grande discussão, tanto doutrinária quanto jurisprudencial, acerca da possibilidade de propor ação rescisória em face da decisão 
concessiva de tutela antecipada antecedente definitivamente estabilizada, ou seja, após o decurso do prazo de dois anos para a propositura da ação exauriente. O debate originou-se pela nomenclatura utilizada pelo legislador, haja vista que este não previu de forma expressa que a tutela, quando estabilizada definitivamente, faz coisa julgada; todavia, previu que a ação rescisória só é cabível em decisões transitadas em julgado que tenham operado os efeitos da coisa julgada, tanto material quanto formal, dando ensejo, assim, a esta celeuma jurídica, bem como a possibilidade de uma decisão provisória tornar-se absolutamente imutável e definitiva em prazo menor que as ações debatidas em caráter exauriente e pleno.

Nesse ínterim, é perceptível a incongruência desta tutela com o ordenamento jurídico brasileiro e, em especial, com a Constituição Federal de 1988 e com o Código de Processo Civil, considerando que estes têm como seus pilares o Estado Democrático de Direito, a igualdade, a paridade de armas, a segurança jurídica, o contraditório e a ampla defesa. Por tal motivo, realizar-se-á uma análise deste importante instrumento processual, bem como da viabilidade da ação rescisória como meio para desconstituição da decisão de concessão de tutela antecipada definitivamente estabilizada.

Ressalta-se que na formulação do presente artigo é utilizado o método indutivo, haja vista a inexistência de uma premissa geral sobre a temática, sendo esta formulada a partir das circunstâncias que se analisa. Destaca-se que os recursos empregados foram exclusivamente bibliográficos, tendo como principais fontes livros, artigos e a legislação brasileira.

\section{Tutelas Provisórias}

Diante da necessidade de dar celeridade ao processo comum e de inverter o ônus do tempo, o legislador criou um meio de regulação provisória da crise de direito, possibilitando que o próprio provimento jurisdicional almejado, ou parte dele, seja alcançado desde logo, ou que sejam asseguradas as condições para que o provimento final seja útil ao demandante. Assim, o Código de Processo Civil traz o Livro V, que trata especificamente das tutelas provisórias, trazendo disposições gerais, comuns a todas as espécies de tutelas provisórias, bem como disposições específicas para cada espécie e subespécie de tutela (GONÇALVES, 2018).

As tutelas provisórias subdividem-se em duas espécies: tutelas de urgência e tutelas da evidência, sendo que aquela tem como requisitos o fumus boni iuris e o periculum in mora, enquanto esta exige apenas o fumus boni iuris para ser concedida. Ressalta-se que ambas admitem que o provimento seja cautelar, visando assegurar pessoas, bens ou direitos para que o provimento jurisdicional final seja útil, ou seja antecipatório, visando possibilitar que o demandante alcance desde logo o bem da vida pretendido com a ação, total ou parcialmente. Ademais, verifica-se que ambas podem ser concedidas liminarmente, inaudita altera pars, com exceção dos casos previstos nos incisos I e IV do artigo 311 do CPC, ou após justificação prévia, com o contraditório prévio à sua concessão (THEODORO JÚNIOR, 2016).

A tutela de urgência, especificamente, divide-se em duas subespécies: tutela de urgência antecipada e tutela de urgência cautelar. Esta possui caráter assecuratório, uma vez que visa a assegurar bens, pessoas ou direitos, enquanto aquela tem caráter satisfativo, haja vista sua confusão, total ou parcial, com o objeto do pedido principal. Ambas podem ser concedidas de forma liminar ou após justificação prévia, bem como de forma antecipada ou incidental, todavia, destaca-se que apenas a antecipada antecedente poderá ser estabilizada, enquanto as demais tem sua efi- 
cácia cessada se não debatidas em cognição exauriente (THEODORO JÚNIOR, 2016).

A tutela de evidência, por sua vez, admite que não exista perigo de dano e risco ao resultado útil do processo, porque se funda na comprovação idônea do direito material de quem a postula. Ante tal privilégio, o legislador elencou quatro situações em que é possível sua concessão, trata-se de rol taxativo que visa assegurar que tal provimento seja concedido apenas nos casos em que se acham reunidos elementos suficientes de convicção do mérito. Ressalta-se que esta modalidade de tutela pode ser concedida liminarmente, ou após justificação prévia, conforme disposto no artigo 311 do CPC, todavia, somente poderá ser concedida em caráter incidental, tendo em conta que pressupõe demanda já ajuizada, diferindo neste ponto, substancialmente, da tutela de urgência, que permite a concessão de forma antecedente, antes do ajuizamento da ação principal (THEODORO JÚNIOR, 2016).

Realizada esta breve distinção entre as espécies e subespécies de tutelas provisórias, cabe analisar de forma mais minuciosa o objeto do presente artigo, qual seja, a tutela de urgência antecipada requerida em caráter antecedente.

\section{Tutela de Urgência Antecipada Requerida em Caráter Antecedente}

Nesta modalidade de tutela, absolutamente sui generis, o pedido da tutela provisória antecede o pedido principal, o demandante pede, liminarmente, que lhe seja concedido o bem da vida pretendido com a ação, de forma integral ou parcial (LAMY, 2018).

A petição inicial deverá trazer, de forma expressa, que o provimento requerido é o previsto no artigo 303 do $\mathrm{CPC}$, bem como que a urgência é contemporânea à propositura da ação. Ademais, considerando que esta tutela se trata de subespécie da tutela de urgência, faz-se preciso a comprovação da fumaça do bom direito e do perigo de dano ou risco ao resultado útil do processo. Deverá também constar na petição inicial uma exposição sumária da lide, devendo a parte autora formular o requerimento da tutela e apenas indicar o pedido de tutela final (ALVIM, 2016).

$\mathrm{O}$ valor da causa deverá ser indicado já no requerimento da tutela provisória e deverá levar em conta o pedido da tutela final, haja vista que, ao ingressar em juízo, o demandante deverá adiantar as custas do provimento jurisdicional como um todo (THEODORO JÚNIOR, 2016).

Caso o juiz entenda que houve o preenchimento dos requisitos legais, concederá a tutela liminarmente; caso entenda que não houve o preenchimento destes requisitos, determinará a emenda da petição inicial no exíguo prazo de cinco dias. Nesse caso, quando realizada a emenda de forma satisfatória, o juiz concederá a tutela e o processo seguirá normalmente, todavia, caso a emenda não sane os defeitos apontados na petição inicial, ou caso não seja realizada a emenda, o processo será extinto sem resolução de mérito, antes da citação do réu. Destaca-se que, nesse caso de indeferimento da tutela, ela só poderá ser postulada novamente se fundar-se em novos motivos, não cabendo sua repetição ad aeternum (THEODORO JÚNIOR, 2016).

No caso do despacho positivo, em que há a concessão da tutela, o réu é citado e intimado para interpor agravo de instrumento em 15 dias. Concomitantemente, o autor é intimado para que realize o aditamento da petição inicial, confirmando o pedido principal e trazendo toda a matéria que pretende discutir de forma exauriente. Se o réu não interpuser o devido recurso, a tutela concedida se estabilizará e o processo será extinto com estabilização da demanda. Todavia, se 
o autor não realizar o aditamento, o processo será extinto sem resolução de mérito, independentemente da interposição de agravo de instrumento pelo réu, e a liminar será cassada, não podendo ser renovada sob os mesmos fundamentos, assim como ocorre no caso de indeferimento da tutela (THEODORO JÚNIOR, 2016).

Havendo o seguimento do processo, será realizada a audiência de conciliação ou mediação, caso a ação verse sobre direitos disponíveis. Na hipótese de não haver acordo, ou sendo incabível a autocomposição, o réu será intimado para apresentação de contestação no prazo de 15 dias, devendo o processo seguir o procedimento comum até chegar à sentença de mérito que resolverá o litígio de forma definitiva, em cognição exauriente, fazendo coisa julgada formal e material (LAMY, 2018).

Todavia, caso o autor adite a petição inicial e o réu reste inerte, não interpondo agravo de instrumento ou interpondo-o intempestivamente, a tutela concedida se estabilizará e o processo será extinto, independentemente da existência de pedidos diversos indicados como objeto da ação principal e não requeridos na tutela provisória, os quais poderão ser novamente postulados em outra demanda. Nesse caso, não se opera a coisa julgada, conforme prescreve o parágrafo $6^{\circ}$, do artigo 304, do CPC. Todavia, a decisão só poderá ser revista, reformada ou invalidada em ação exauriente, proposta por uma das partes no prazo decadencial de dois anos. Decorrido este, haverá a estabilização definitiva da demanda (LAMY, 2018).

\section{Estabilização da Tutela, Ação Exauriente e Ação Rescisória}

A estabilização da tutela de urgência satisfativa requerida em caráter antecedente traz uma nova luz ao direito brasileiro, haja vista a possibilidade desta, mesmo sem cognição plena, vir a regular a crise de direito material por tempo indeterminado e até mesmo de forma definitiva. Ressalta-se que após a estabilização há a abertura do prazo de dois anos para a propositura da denominada ação exauriente, em que qualquer uma das partes pode propor ação principal de cognição plena visando rever, reformar ou invalidar a medida provisória estabilizada. $\mathrm{Na}$ hipótese de nenhuma das partes proceder à sua propositura, a tutela tornar-se-á definitivamente estável, pois o referido prazo é decadencial, havendo o perecimento do direito subjetivo de ambos (THEODORO JÚNIOR, 2016).

Assim, em face da tutela definitivamente estabilizada não será cabível a propositura de ação exauriente; contudo, a princípio, também não será possível a propositura de ação rescisória, considerando que o legislador afirma que esta não fará coisa julgada. Não obstante, ao analisar substancialmente o caráter da estabilização definitiva da tutela antecipada antecedente, verifica-se que esta possui extrema semelhança com a coisa julgada, considerando que ambas são decisões irrecorríveis e imutáveis, que visam a dar segurança jurídica às decisões judiciais, evitando que os conflitos se protraiam no tempo. Nesse ínterim, surge um dos maiores questionamentos acerca da tutela antecipada requerida em caráter antecedente: a possibilidade de propor ação rescisória após a estabilização definitiva (LAMY, 2018).

A fim de resolver tal questionamento, inúmeros doutrinadores criaram suas teses. Dentre elas, inúmeras são negativas, defendendo a impossibilidade de propositura de ação rescisória, considerando que o legislador foi claro ao fazer constar no texto da lei que a tutela estabilizada não faz coisa julgada (GUIMARÃES, 2018). Assim, sob um viés estritamente legalista, há quem defenda que uma vez definitivamente estabilizada a tutela antecipada torna-se absolutamente imutável 
(SICA, 2015), fundamentando que a sentença que extingue o processo é considerada terminativa e que na estabilização qualificada não se verifica a função positiva da coisa julgada, qual seja, o dever de observar a decisão prolatada em processos futuros entre as partes (GOUVEIA FILHO; PEIXOTO; COSTA, 2016).

Em posição intermediária, aparecem os estudiosos que defendem a possibilidade de propor uma ação destinada a debater o mérito, assim como a ação exauriente, dentro do prazo prescricional ou decadencial do direito material, mesmo após o transcurso do prazo de dois anos para a propositura da ação exauriente (MITIDIERO, 2015). Todavia, também defendem a impossibilidade de propositura de ação rescisória, porque entendem inexistir formação de coisa julgada a partir da tutela antecipada requerida em caráter antecedente definitivamente estabilizada (WAMBIER, 2015).

Verifica-se que ambas as teses defendem a impossibilidade de propositura de ação rescisória ante a negativa da formação da coisa julgada material, todavia, ao negar esta possibilidade, tornam a estabilização mais hígida que a coisa julgada, haja vista que esta tonar-se-ia integralmente inimpugnável no exíguo prazo de dois anos, não podendo ser atacada por qualquer tipo de ação. Ademais, no tocante à segunda tese levantada, verifica-se a total incompatibilidade com os dispositivos legais do artigo $304, \S 5^{\circ}$, do CPC, uma vez que o legislador foi preciso ao determinar que o prazo para propositura de ação exauriente decai em dois anos, sendo incabível a propositura de ação análoga após o transcurso deste prazo (REDONDO, 2015).

Em posição antagônica às teses acima expostas, surgem operadores do direito que defendem a possibilidade de propositura de ação rescisória, considerando que, apesar de não ser denominada como coisa julgada, a tutela definitivamente estabilizada opera os mesmos efeitos que aquela (LESSA, 2016). Ponderando que, após a prazo de dois anos, a estabilidade se torna imutável, sendo forçoso concluir que não há formação de coisa julgada material, haja vista que esta é o fenômeno que impede a propositura de novas demandas que busquem modificar o julgamento de mérito anterior (REDONDO, 2015).

Destarte, realizando uma interpretação teleológica do tema à luz do Código de Processo Civil, com especial enfoque na Constituição da República Federativa do Brasil, grande parte dos juristas defende que os institutos da coisa julgada e o da tutela antecipada estabilizada devem prevalecer, a fim de que seja garantida a segurança jurídica, o processo justo, a paridade de armas, o contraditório e a ampla defesa, bem como os demais princípios orientadores do Código de Processo Civil e do Estado Democrático de Direito (LAMY, 2018).

A partir da análise anteriormente realizada, infere-se que, apesar da celeuma jurídica criada em torno da possibilidade da propositura de ação rescisória em face de tutela antecipada requerida em caráter antecedente definitivamente estabilizada, faz-se necessário que os operadores do direito façam uma análise cuidadosa de cada um dos casos que se apresentarem, optando por uma visão integrada do ordenamento jurídico (MINAS GERAIS, 2016). Como bem ensina Eduardo Lamy (2018, p. 109): “a leitura do NCPC acerca da estabilização da tutela antecipada de caráter antecedente deve ser feita à luz da Constituição, respeitando-se os princípios nela instituídos para um exercício democrático no processo civil".

\section{Conclusão}

Pode-se afirmar que a tutela provisória veio para dar maior guarida aos princípios constitucionais e processuais, uma vez que 
garante a celeridade processual aliada ao devido processo legal, oportunizando que a prestação jurisdicional seja eficaz. Dentre as espécies e subespécies, cada qual com regras e procedimentos específicos, destaca-se a tutela de urgência antecipada requerida em caráter antecedente, em especial pela possibilidade de resolução da crise de direito material, de forma definitiva, com base na probabilidade e na sumariedade.

Nesse toar, constatou-se clara divergência entre as três principais correntes doutrinárias. Uma leitura constitucional dos artigos $303 \mathrm{e}$ 304 do Código de Processo Civil, bem como do instituto da coisa julgada é a mais acertada. Considerando que o sistema jurídico brasileiro tem como preceito fundamental a Constituição de 1988, todas as demais legislações devem a ela se adequar e nela obter sua interpretação e funcionalidade. Assim, visando a dar aplicabilidade prática à tutela antecipada antecedente, é preciso uma leitura teleológica, admitindo-se que a estabilização definitiva faz coisa julgada material, perante a qual é possível a propositura de ação rescisória.

Por fim, infere-se que este importante instituto de autonomização da tutela sumária necessita de especial atenção dos juristas, haja vista que, apesar de não restar consolidado o entendimento aqui defendido, faz-se preciso a defesa e consagração deste, sob pena dessa modalidade de tutela ser declarada inconstitucional e, consequentemente, ser extinta do mundo jurídico, restando, assim, perdido esse importante avanço do direito processual brasileiro, que permite a cognição sumária pôr fim ao processo.

\section{REFERÊNCIAS}

ALVIM, E. A. Tutela provisória. 2. ed. São Paulo: Saraiva, 2016.

GONÇALVES, M. V. R. Direito Processual Civil: Esquematizado. 9. ed. São Paulo: Saraiva, 2018.

GOUVEIA FILHO, R. P. C.; PEIXOTO, R.; COSTA, E. J. F. Estabilização, imutabilidade das eficácias antecipadas e eficácia de coisa julgada: uma versão aperfeiçoada. Revista eletrônica de direito processual. a. 10. v. 17. UERJ. Rio de Janeiro, 2016. Disponível em: https://www.epublicacoes.uerj.br/index.php/redp/article/view/26611. Acesso em: 04 jul. 2019.

GUIMARÃES, M. C. Estabilização da tutela antecipada antecedente: (im)possibilidade de desconstituição por ação rescisória. 2018. 55 f. Monografia (Graduação em Direito). Faculdade Damas. Recife, PE, 2018. Disponível em: http://faculdadedamas.edu.br/revistafd/index.php/ academico/article/view/938. Acesso em: 04 de jul. 2019.

LAMY, E. Tutela provisória. São Paulo: Atlas, 2018.

LESSA, G. T. Críticas à estabilização da tutela: a cognição exauriente como garantia de um processo justo. Revista de processo. a. 41. v. 259. Thomson Reuthers Revista dos Tribunais. São Paulo, 2016. Disponível em http: //www.academia.edu/download/49428579/CRITICAS_A_ESTABILIZACAO_ DA_TUTELA__REPRO_259.pdf. Acesso em: 04 jul. 2019.

MINAS GERAIS. Tribunal de Justiça. Cadernos da EJEF: Curso jurídico do novo CPC. TJMG. Belo Horizonte, 2016. Disponível em: http://bd.tjmg.jus.br/jspui/bitstream/tjmg/7752/1/Miolo\%20 Curso\%20Juridico\%20do\%20Novo\%20CPC.pdf\#page=243. Acesso em: 04 jul. 2019.

MITIDIERO, D. Autonomização e estabilização da antecipação da tutela no novo código de processo civil. TST. Brasília, 2015. Disponível em: https://juslaboris.tst.jus.br/bitstream/ 
handle/1939/91449/2015_mitidiero_daniel_autonomizacao_estabilizacao.pdf?sequence=1. Acesso em: 04 jul. 2019.

REDONDO, B.G. Estabilização, modificação e discussão da tutela de urgência antecipada antecedente: principais controvérsias. Revista de processo. Thomson Reuthers Revista dos Tribunais. São Paulo, 2015. Disponível em: http://www.academia.edu/download/38245314/ Bruno Garcia_Redondo_REPRO_244_Tutela_de_urgencia_antecipada_antecedente.pdf. Acesso em: 04 jul. 2019.

SICA, H. V. M. Doze problemas e onze soluções quanto à chamada "estabilização da tutela antecipada". Revista do Ministério Público do Rio de Janeiro. Rio de Janeiro, 2015. Disponível em: https://edisciplinas.usp.br/pluginfile.php/2458338/mod_resource/content/ 0/2015\%20-\%20 Doze $\% 20$ problemas $\% 20 \mathrm{e} \% 20$ onde $\% 20$ solu $\%$ C3\%A7\%C3\%B5es $\% 20$ quanto $\% 20 \% \mathrm{C} 3 \% \mathrm{~A} 0 \% 20$ estabiliza\%C3\%A7\%C3\%A3o\%20da\%20tutela\%20antecipada.pdf. Acesso em: 04 jul. 2019.

THEODORO JÚNIOR, H. Curso de Direito Processual Civil: Teoria geral do direito processual civil, processo de conhecimento e procedimento comum. 5. ed. Rio de Janeiro: Forense, 2016.

WAMBIER, L. R.; et al. Primeiros comentários ao novo código de processo civil: artigo por artigo. São Paulo: RT, 2015. 